\title{
Development Strategy of Health Tourism in Iran
} \author{
Anabad $^{4}$, Zahra Hashemidehaghi, ${ }^{5,}$, \\ ${ }^{1}$ Department of Health Services Management, Tehran North Branch, Islamic Azad University, Tehran, Iran \\ ${ }^{2}$ Health Research Center, Baqiyatallah University of Medical Sciences, Tehran, Iran \\ ${ }^{3}$ Shahid Beheshti University of Medical Sciences, Tehran, Iran \\ ${ }^{4}$ Department of Epidemiology, School of Public Health, Iran University of Medical Sciences, Tehran, Iran \\ ${ }^{5}$ Eye Research Center, Tehran University of Medical Sciences, Tehran, Iran \\ ${ }^{6}$ Department of Health Services Management, Tehran South Branch, Islamic Azad University, Tehran, Iran
}

Seyed Mojtaba Hosseini' ${ }^{1}$, Ali Maher ${ }^{1}$, Omidreza Safarian${ }^{1}$, Ali Ayoubian², Donya Sheibani-Tehrani ${ }^{3}$, Hossein Amini-

*Corresponding Author: Zahra Hashemidehaghi, Ph.D. Student in Healthcare Services Management, Eye Research Center, Tehran University of Medical Sciences, Tehran, Iran. Email: hashemi_mitra@yahoo.com

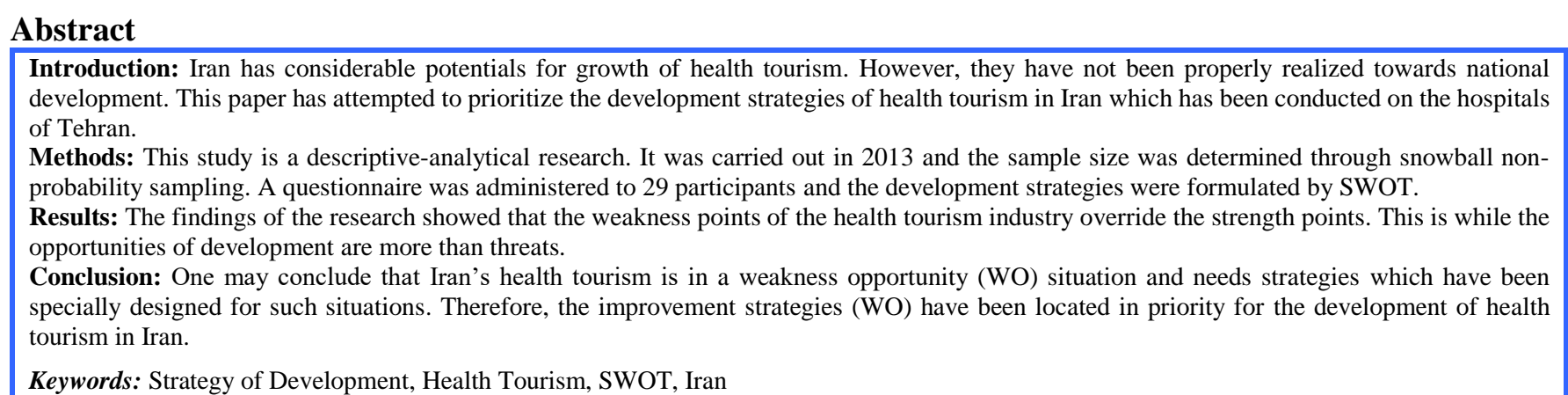

Article History: Received: 1 May. 2015; Accepted: 26 Jul. 2015; Online Published: 26 Nov. 2015

Cite this article as: Hosseini SM, Maher A, Safarian O, Ayoubian A, Sheibani Tehrani D, Amini-Anabad H, et al. Development strategy of health tourism in Iran. Int J Travel Med Glob Health. 2015;3(4):153-8.

\section{Introduction}

Health tourism is one of today's highly thriving sections of the tourism industry in the world. It is one of the interesting industries in connection with economic, employment, cultural interactions, and even political advantages $[1,2]$.

Health tourism emerged in the 1990s when a few factors contributed in preparing the ground. People in the developed countries were challenged with high costs of medical services and slow services so that it would have taken ages to secure insurance confirmations. Consequently, people started to look for medical services in other countries. In 2003, India, Malaysia, and Thailand hosted 4.1 million medical travelers and enjoyed over $\$ 1$ billion income. The number of the international patients reached 5.2 million in 2005 and the emerged market nowadays is worth $40-60$ billion dollars and experiences a $20 \%$ annual growth [3-5].

Estimates suggest that 750000 US citizens traveled abroad to seek medical attention in 2007 [6]. Expensive medical services in the USA and the European countries have motivated many patients of these countries to look for medical services in other countries. Consequently, a surge in the number of health tourists has occurred in the recent years. The results of a recent study showed that cost of surgeries in Malaysia, India, Thailand, Singapore, and Korea is from $30 \%$ to $70 \%$ (even $80 \%$ is some cases) less than those in the USA. Quality is one of the key factors in the growing industry. No industry may survive without improving services. Although, citizens of rich and developed countries choose developing countries to receive medical services for the low prices, they never neglect quality concerns $[7,8]$.

Literature review indicates that the Persian Gulf countries are the largest potential market for Iran medical tourism given religious and cultural similarities between these nations [9]. Cost considerations are one of the biggest motivations of health tourism and, fortunately, costs of medical services in Iran are lower than the other neighbor targets for health tourists (e.g. Turkey, India, and so on) [10].

Crude oil export is the main source of foreign exchange income and considering the problems of the dependence on oil export income, investment in other products and services that can create foreign exchange inflow is essential. Iran has great potentials for producing and providing specific products and services and reasonable investment can realize these potentials as a source of foreign exchange. Also, regarding the potentials of health tourism in Iran, in this paper the main strength in this field is the low costs of health tourism services in Iran (medical services, hospitalization, etc.). Without any doubt, health tourism is one of these services. According to Iran's 20 years outlook "Iran must be the first target of health tourism in the region." Thus, Iran has to become the center of providing health and medical services in the region before attracting 20 million health tourists and earning $\$ 15$ billion income $[11,12]$.

Through formulating a reasonable utilization of realized and potential capacities in tourism, medicine, and health fields, Iran can emerge as a center of health tourism in Asia. However, the country has failed to take these opportunities in absence of a systematic and integrated program [13]. Moreover, development in the field of health tourism and implementation of an effective management needs infrastructural works. Similar experiences by other countries suggest that long-term planning in the tourism field can lead to advantages and market development without facing serious challenges. 
Top managers of the country need to develop this attitude that international business arena is an intense competition field where by adopting proper strategies any tactical error can be dealt with effectively and expect success [6].

Taking its advantages in health tourism such as low costs of health services and high quality of services, Iran is planning to grab the opportunities although challenges ahead are not negligible. The present study has aimed to determine the current situation of health tourism in Iran and to propose effective strategies towards taking the first place in the region and also spot probable challenges.

The present study was conducted to discover the relation between physical access in emergency wards and the time patients have to wait before being served in Tehran hospitals.

\section{Methods}

This research is descriptive-analytical and also a kind of applied research and it was carried out in 2012 as an attempt to prioritize development strategies of Iran's health tourism. This research has been done upon the hospitals of Tehran in Iran. Also, the Delphi method and experts' opinions in the field of health tourism and health services such as those in universities, Ministry of Health, Treatment and Medical Education, Cultural Heritage and Handcrafts Org., and International Travel Center of Iran were used to identify the sets of internal and external factors. After the identification of these factors (internal and external), weighting was accomplished through factors and criteria. The total weight of the internal and external factors of each obtained number 1 and these factors are rated from 1 to 4 . In order to obtain the final score, the weight of each factor was multiplied to its rating and the results were put in the weight score section. In this research, the strategic model of SWOT was used to find the internal and external factors such as the weakness and strength points and the opportunities and threats facing the development of health tourism in Iran.

\subsection{The Instrument}

The internal factors (strengths and weaknesses) and external factors (threats and opportunities) effective in health tourism were identified though library studies, the Internet surfing, and interviewing the experts and then designed into a questionnaire. The questionnaire was reviewed by experts and the content and face validity were confirmed.

\subsection{Data Gathering and Analysis}

Without comprehensive knowledge of the study population and due to the lack of a sampling framework, snowball nonprobability sampling was used for sampling and the participants were asked to introduce other knowledgeable candidates. Through this, 85 candidates constituted the study population and 35 of them received the questionnaire. Eventually at the end, 29 questionnaires were filled out and then returned.

To formulate the development strategies of health tourism, the SWOT analyzing method was used. As the method requires, an effective strategy is the one that as result of its implementing, the opportunities and strength points are maximized and the weaknesses and threats are minimized. At the end, a list of strengths and weaknesses, as the internal factors, and another list of opportunities and threats, as external factors, were developed. To analyze the key elements of the internal/external environment, internal factor evaluation (IFE) matrix and external factor evaluation (EFE) matrix were created. Afterwards, the internal/external (IE) factors matrix is created, which represents the status of the system. Finally, by using the SWOT matrix, the factors were compared pair wise and four strategies (WT/ST/WO/SO) were recommended for the development of the industry both at macro and micro levels.

\section{Results}

\subsection{IFE Matrix}

The key factors - i.e. strength and weaknesses points - of the internal factors were first identified. The matrix was created through the following steps:

- List the main strength and weakness points

- Assign coefficients to the elements from zero (unimportant) to one (very important) so that the sum of the coefficients must be equal to 1

- Score each factor from 1 to 3 , so that $1=$ complete weakness; 2 = relative weakness; 3 = relative strength; and 4 = complete strength

- Multiply the score and coefficient of each factor to obtain the final coefficient

- The final point of the internal factors are obtained from the sum of the final points

- When the final point of the internal factor in the evaluation matrix is higher than 2.5 (the mean of 1 and 4), then the strength points are more than the weakness points. Otherwise, the strength points are more than the weakness points.

The IFE matrix is represented in Table 1. Total final point of 2.21 indicates that the weaknesses override the strengths.

\subsection{EFE Matrix}

The key factors recognized as the opportunities and threats were listed, by evaluating the external factors. Following the procedure discussed in step one, the factors were scored from 1 to 4 . This means, 1 stands for poor reaction and 4 stands for the best reaction. When the final point of the external factor in the evaluation matrix is higher than 2.5, the strength points are more than weakness points. Otherwise, the strength points are more than the weakness points.

\subsection{Internal/External Factors Matrix}

Based on the IFE and EFE matrices, the status of the subject is determined as one of the four possible situations: strength opportunity (SO), weakness opportunity (WO), strength threat (ST), and weakness threat (WT). To this end, the sum of final points of IFE matrix and sum of final points of EFE are placed on $\mathrm{X}$ and $\mathrm{Y}$ axes respectively. The coordination system indicates the status of each factor. Given the points listed in Table 1 and Table 2, and Diagram 1, Iran's health tourism is located at WO position. This position calls for taking the opportunities in the external environment to cover the internal weaknesses. It is notable that we have only found the strategic condition for the specific time period under study (Diagram 1).

\subsection{SWOT Matrix}

These factors are based on the internal strength/weakness points and external opportunities and threats lists (tables above). The results of the comparisons are listed in Table 3 as WT/ST/WO/SO strategies. Each strategy is interpreted briefly in what follows:

1. Strength and opportunity (SP) strategy: Strength points are employed to grab the external opportunities.

2. Weakness and opportunity (WO) strategy: The opportunities in the external environment are employed to cover the internal weakness points.

3. Strength and threats (ST) strategy: The effects of the external threats are attenuated by the strength points.

4. Weaknesses and threats (WT) strategy: The internal weakness points are attenuated to avoid external threats. 
Table 1. Internal factors evaluation matrix

\begin{tabular}{|c|c|c|c|c|}
\hline No. & Strength Points & Coefficient & $\begin{array}{c}\text { Point } \\
5<X<1\end{array}$ & $\begin{array}{l}\text { Final } \\
\text { Point }\end{array}$ \\
\hline S1 & availability of state of the art medical equipment in Iran (both quantitatively and qualitatively) & 0.05 & 4 & 0.2 \\
\hline $\mathrm{S} 2$ & knowledgeable physicians and international reputation in the hospitals & 0.04 & 3 & 0.12 \\
\hline S4 & technological capacity of Iran to attract health tourists & 0.05 & 1 & 0.05 \\
\hline S5 & good accommodation facilities & 0.05 & 1 & 0.05 \\
\hline S6 & transportation & 0.03 & 2 & 0.06 \\
\hline \multirow[t]{2}{*}{ S7 } & four seasonal climate & 0.02 & 3 & 0.06 \\
\hline & Weaknesses & & & \\
\hline W1 & poor quality control over services in health tourism centers & 0.03 & 1 & 0.03 \\
\hline W2 & unattractive design of the website that introduce health tourism potentials of the country & 0.05 & 1 & 0.05 \\
\hline W3 & $\begin{array}{l}\text { ineffective public information services to inform international medical communities and failure to take part } \\
\text { in international exhibits }\end{array}$ & 0.04 & 3 & 0.12 \\
\hline W4 & lack of general programs to set objectives of medical tourism in Iran & 0.08 & 1 & 0.08 \\
\hline W5 & small share of private sector in health tourism activities & 0.05 & 1 & 0.1 \\
\hline W6 & ineffective follow up services to check the patients when they return to their country & 0.04 & 4 & 0.16 \\
\hline W7 & poor performance concerning introducing Iran natural and medical potential at international level & 0.04 & 3 & 0.12 \\
\hline W9 & lack of international credit card services in Iran & 0.03 & 1 & 0.03 \\
\hline W10 & poor performance of Iranian embassies in other countries regarding Iran's health tourism potentials & 0.02 & 1 & 0.02 \\
\hline W11 & negligence of the customer's recommendations and complaints & 0.01 & 4 & 0.04 \\
\hline W12 & poor coordination and communication between the entities in charge of health tourism activities & 0.02 & 3 & 0.06 \\
\hline W13 & failure to use results of marketing research in health tourism sector & 0.03 & 2 & 0.06 \\
\hline W14 & tight budget dedicated to health tourism development & 0.04 & 2 & 0.08 \\
\hline W15 & no international medical coverage in Iran & 0.03 & 1 & 0.03 \\
\hline W16 & underdeveloped infrastructures & 0.04 & 4 & 0.16 \\
\hline W17 & lack of privileges for health tourists to enter and leave the country & 0.02 & 4 & 0.08 \\
\hline W18 & no medical visa program for health tourists & 0.05 & 1 & 0.05 \\
\hline W19 & failure of the ministry of health to keep the record of health tourists & 0.01 & 4 & 0.04 \\
\hline \multirow[t]{2}{*}{ W20 } & lack of diagnostic and treatment clinics (with international standards) & 0.03 & 2 & 0.06 \\
\hline & Total & 1 & - & 2.21 \\
\hline
\end{tabular}

Table 2. External factors evaluation matrix

\begin{tabular}{|c|c|c|c|c|}
\hline No. & Strength Points & Coefficient & $\begin{array}{c}\text { Point } \\
5<X<1\end{array}$ & Final Point \\
\hline $\mathrm{O} 1$ & growth of tourism industry around the world & 0.05 & 3 & 0.15 \\
\hline $\mathrm{O} 2$ & vicinity to wealthy nations of Persian Gulf & 0.05 & 2 & 0.1 \\
\hline $\mathrm{O} 3$ & legal limitations imposed on specific type of surgeries in the Islamic countries of the region & 0.03 & 2 & 0.06 \\
\hline $\mathrm{O} 4$ & religious and cultural similarities with countries of the Middle East & 0.04 & 3 & 0.12 \\
\hline O5 & aging population of the world and growth of demand for medical attentions & 0.05 & 2 & 0.1 \\
\hline O6 & high demand for medical services in the neighbor and Central Asia countries & 0.07 & 4 & 0.28 \\
\hline \multirow[t]{2}{*}{$\mathrm{O} 7$} & high potential of health tourism & 0.07 & 4 & 0.28 \\
\hline & Threats & & & \\
\hline $\mathrm{T} 1$ & small share of Iran health tourism of the world market & 0.08 & 3 & 0.24 \\
\hline $\mathrm{T} 2$ & several political and economic sanctions imposed by the international entities & 0.08 & 3 & 0.24 \\
\hline T3 & recent world economic depression & 0.1 & 4 & 0.4 \\
\hline $\mathrm{T} 4$ & strong and experienced international competitors in Asia & 0.06 & 2 & 0.12 \\
\hline T5 & Low costs of services in some of Asian competitors (India, Malaysia, etc.) & 0.05 & 2 & 0.1 \\
\hline T6 & variety of health tourism services by Asian competitors & 0.06 & 3 & 0.18 \\
\hline T7 & poor advertisement & 0.05 & 3 & 0.15 \\
\hline T8 & recent initiatives taken by the Persian Gulf countries to attract health tourists of the region and the world & 0.06 & 3 & 0.18 \\
\hline \multirow[t]{2}{*}{ T9 } & reluctance to travel to Iran among health tourists from Western and developed countries & 0.1 & 3 & 0.3 \\
\hline & Total & 1 & - & 3 \\
\hline
\end{tabular}

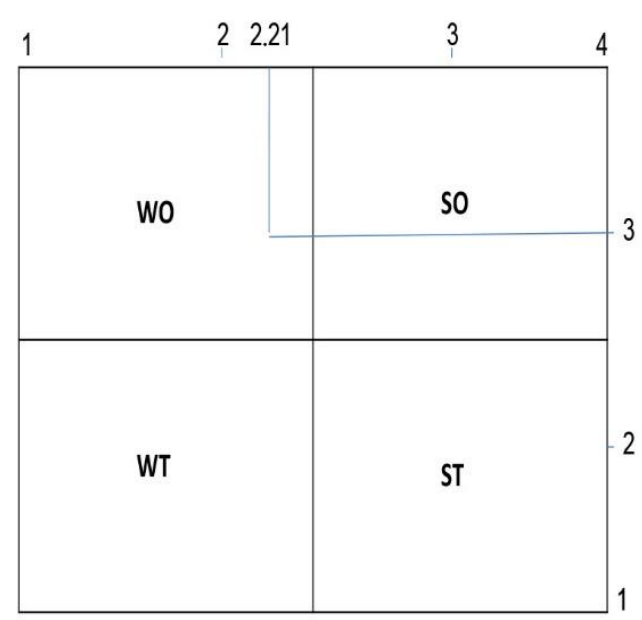

Diagram 1. Internal/external factors matrix 
Opportunities (O)

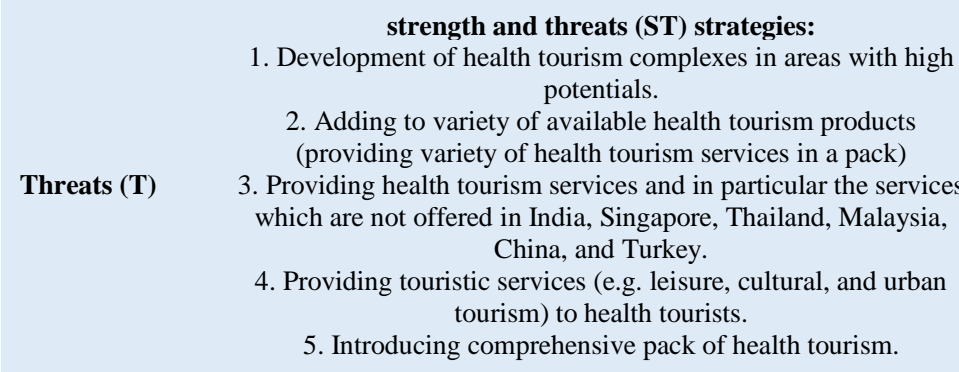

health tourism attractions through development of products and services.

4. Government's support of any investment in hardware or software fields pertinent to health tourism. and institutionalization of trainings needed to provide services
Strength and opportunity (SO) strategy:

1. Filling in more important role in regional markets including

recently established republics of Central Asia, Iraq, Afghanistan, and Pakistan.

2. Development of new geographical markets especially where higher potentials are available

\section{Weakness Points (W)}

Weakness opportunity (WO) strategy:

1. Harmonized and stable development of health tourism in areas of high potentials

2. Privatization of health and treatment sector.

3. Cutting expenditures and offering cheap health tourism plans

4. Attracting health tourism throughout the year.

5. Providing higher quality services for lower prices by using

health tourism services provided by authorized companies.

5. Initiation of cooperation with other countries in health tourism

6. Utilizing state of the art technologies to support health tourism in Iran.

7. Reviewing and developing comprehensive strategy to develop health tourism in Iran.

Weakness and threats (WT) strategy:

1. Entering international cooperation in technical and technological fields and commissioning research and development of products to research institutes.

2. Cooperating with leading countries in health tourism to implement extensive project and attracting foreign investment. 3. Investing in regions with good climate, hot/cold springs with the state support, attracting public investment and taking loan from international institutes.

4. Improving image of Iran in the world by adopting proper diplomacy, advertisement, and running health tourism department in Iranian embassies.

\section{Discussion}

The research findings, the results of analyzing the key factors of internal and external environment, and IFE and EFE matrixes showed that Iran's health tourism industry, at the time of doing the study, had 7 strength points and 20 weakness points. With total final point of 2.21 , the internal factors indicated that the weakness points exceeded the strength points. Furthermore, among the internal factors, the availability of the latest medical equipment and facilities, Iranian physicians with international reputation, and low cost of health services were the most critical advantages. On the other hand, no study on the target groups of the industry in R\&D section, poor follow up services after the patient leaves country, and poor infrastructures were the most critical weakness points. It is notable that the industry is faced with 7 opportunities and 9 threats, so that with final point of 3 , the opportunities override the threats ahead of development of Iran's health industry. Therefore, the sample strategy for development of health tourism in Iran in this paper is Improve strategy (WO) that includes: harmonized and stable development of health tourism in areas of high potentials, privatization of the health and treatment sector, cutting expenditures and offering cheap health tourism plans, attracting health tourism throughout the year, providing higher quality services for lower prices by using health tourism services provided by authorized companies, utilizing state of the art technologies to support health tourism in Iran, reviewing and developing a comprehensive strategy to develop health tourism in Iran. In order to succeed in this branch of tourism, the guidelines must improve in this section. Regarding the external factors, high demand in neighbor and the Central Asia countries was the key opportunity and reluctance of health tourists from the Western and developed countries to travel to Iran and global economic depression were the main threats.

Izadi et al. [8] believe that low costs of medical services comparing with world and regional competitors and abundance of medical academies to supply human resources to the health sector as the main advantages of Iran. According to Tourani et al [14] lower costs of health services and accommodation attract many patients from the region and Asian countries to Thailand and Malaysia. Mirfakhrediny et al. [15] used the Servqual model in his study in Yazd, Iran and concluded that enough equipment and quality medical services were two main strength points of health tourism. Ranjbaran [16] ranked the internal/external factors of tourism (foreign tourists were under study) in Isfahan, Iran using the fuzzy hierarchy analysis and considered the growth of the tourism industry around the world as the main opportunity. Rokni et al. [9] evaluated the potentials of health tourism in Shiraz, Iran from the viewpoint of the top managers of target hospitals and realized that cultural and religious similarities are the main reasons that health tourists in the region choose Iran. Results of these studies are consistent with the present study concerning the advantages and weaknesses of Iran health tourism. It is noticeable that Ferdosi et al. conducted a systematic review of the published articles in the field of health tourism between 2000 and 2011. They found that the studies carried out in the developing countries are mainly focused on the benefits of health tourism while those conducted in the developed countries discuss the threats of health tourism such as unclear treatment procedure and poor follow up services that may cause side effects after the treatments [17].

Studies on the challenges and obstacles ahead of health tourism like the one carried out by John [18] using the ISM model highlighted the lack of understanding between the service providers and service receivers, communication problems, distrust, cultural differences, irrational reactions, and following clichés as the main challenges. In addition, Izadi et al [9] mentioned poor coordination between the authorities, lack of comprehensive information system to monitor health tourists, inefficient public information measure to promote Iran's capacities, insufficient infrastructures, and lack of laws' support as the main challenges ahead of health tourism in Iran. Delgoshaei et al [19] used diamond advantages to survey challenges of Iran's health tourism and found problems concerning the infrastructures, government support, development program, inter-sector coordination and cooperation at macro/operational levels, clinics that meet international 
standards, integrated promotion and advertisement plans. Quality and safety concerns regarding transportation system was highlighted by Ranjbarani et al [16] as the main weakness of Iran health tourism. They also mentioned sanctions and negative anti-Iran campaign by the West as the most critical threats. According to Mirfakhredini et al [15], the factor of accommodation services for those in attendance on the patient obtained the minimum points. Azadi et al [20] concluded in their study on quality of public and private hospitals located in Tehran from the health tourist's viewpoint that although the total point of the hospitals were above the mean point, poor communication between the staff and the tourists (poor English knowledge of the staff) is a challenge. Khodaiar Zernegh et al [21] evaluated capabilities of selected hospitals located in Tehran to attract health tourists and based on the patient-oriented standards of Joint Commission International (JCI) concluded that in spite of the fact that average point was higher than mean point, the hospitals needed further programming and implementation of development plans regarding patient/family's rights and patient care and training standards. Failure to meet international standards by clinics, accommodation facilities, and medical equipment were mentioned by Khoshmohabat [22] as the key factors effective in underdevelopment of health tourism in Iran [19]. According to Tourani et al [14], the main challenges ahead of health tourism in ASEAN region (Malaysia, Singapore, and Thailand) can be found in areas such as international rating of clinics and standards, international insurance coverage, support for the private sector, cooperative attitudes of the public sector, and legal problems that harden traveling in the region for the tourists and the experts.

As mentioned earlier, Iran's health tourism is at a WO situation - i.e, according to the IE factors matrix. It is said that the available opportunities in the external environment must be used to improve the internal weaknesses. Hajinejad et al. [10] studied health tourism development strategies in Shiraz, Iran through the SWOT matrix. They obtained a total final points of internal and external factors equal to 2.53 and 2.81. Thus, the effective proposed strategy was WO strategy.

Taking into account the SWOT matrix and that, WO strategies are best options, seven strategies were proposed for the development of Iran's health tourism. Harmonized and stable development of health tourism in the south of the country; minimizing the government's role in the health sector; cutting costs and offering discount packs to health tourists; advertising to attract health tourist throughout the year; giving room to domestic and foreign enterprises to provide quality and less expensive services to health tourists; preparing the ground to use state of the art technology to support health tourism in Iran; and the modification of programs and codifying comprehensive strategies to develop health tourism in Iran are the proposed strategies.

Variety of techniques has been used by other studies to propose strategies and determine the factors effective in the development of health tourism in Iran. It is notable that the majority of the factors mentioned in other studies are also noted as internal or external factors in the present paper. Morovati Sharifabadi et al. [23] used the fuzzy TOPSIS technique and interpretational structural model (ISM) the in Yazd Province, Iran. They argued that updated hospital staff and assigning physicians to their field of expertise is the main factors in the development of health tourism. Hadizadeh Moghadam et al. [24] illustrated that the cost of the services, waiting time, availability of the variety of treatments and medical equipment, and social factors had a significant and positive effect on the health tourists to choose Iran. On the other hand, they showed that quality of the services, political and security concerns, ease of traveling to Iran, and touristic attractions had no significant effect. Ormond [25] used the SEM technique and found that competitive capabilities of the target country and quality of the services have considerable effects on the mental image of health tourists in Malaysia. Moreover, Aref [26] used the path analysis and multivariate regression test in their study in Shiraz, Iran and argued that all the factors of quality, culture facilities, information and telecommunication technology (ITC) had both direct and indirect positive effects on the development of health tourism. In a study conducted by Ormond [25] it was concluded that there was a strong relationship between costs, quality of services, type of treatment, access to the treatment, and marketing on one hand and perception of the health tourist regarding the destination on the other. Tabibi et al. [27] argued that the only significant relationship regarding public information mechanism was found between advertisement in the mass media and attracting health tourists, while other mechanisms (e.g. brochure, pamphlet, guide book, etc.) had no effects in attracting health tourists.

\section{Conclusion}

The propose of strategies and approaches to develop health tourism in Iran, the strengths, weaknesses opportunities and threats ahead of Iran's health tourism were surveyed by using the SWOT matrix. Based on the results, few strategies were proposed to improve health tourism, which are as followed. Taking measures in the field of macro managerial programming to prepare the infrastructures of the health tourism industry. Coordination among the authorities of health tourism, commissioning research and studies on the industry at international levels, organizing and investing in measures of stepping towards international standards in the industry and pertinent fields such as transportation, hotels, accommodation services, advertisement. Participating in exhibitions using the local language of the target groups to introduce capabilities of the country in medical fields, introducing other touristic attractions, opening joint offices with other active enterprises in the field in other countries to facilitate communications, setting travel plans, securing visa, and booking airline. Running websites to introduce capabilities of the country and listing the prices of the services so that the visitors could compare the prices, supervising prices and quality of the services and to remove the dealers, running health facility websites to provide reservation services, consulting the patients, and providing follow up services, opening tourism department in hospitals to facilitate issuance of visa, exchange services and booking airlines.

\section{Acknowledgements}

This research was self-funded. We would like to thank all of the people who made direct or indirect contribution in doing the study and composing the article .

\section{Authors' contributions}

All the authors participated in designing the research. A.A and M.Z were responsible for the study concept and design and for writing the first draft. Z. H. was responsible for the analysis and prepared the draft of the manuscript. All authors 
participated in reading and revising the draft and preparing the final version for submission.

\section{Financial disclosure}

The author declares no financial disclosure.

\section{Funding/Support}

This study was self-funded.

\section{References}

1. Izadi M, Ayoubian A, Saadat SH, Zarnaq RK, Abbasi S, Moein N, et al. Medical travel: the ethical and legal challenges. Int J Travel Med Glob Health. 2013;1(1):23-8.

2. Shafaghat T, Jabbari AR, Kavoosi Z, Ayoubian A, Zarchi MKR. The capabilities of Iranian hospitals in attracting medical tourists; Based on Joint Commission International: A case study of Shiraz hospitals. Int J Travel Med Glob Health. 2014;2(1):5-9.

3. Hanefeld J, Smith R, Horsfall D, Lunt N. What do we know about medical tourism? A review of the literature with discussion of its implications for the UK National Health Service as an example of a public health care system. J Travel Med. 2014;21(6):410-7.

4. Ayoubian A, Tourani S, Dehaghi ZH. Medical Tourism Attraction of Tehran Hospitals. Int J Travel Med Glob Health. 2014;1(2):95-8.

5. Izadi M, Saadat SH, Ayoubian A, Dehaghi ZH, Karbasi MR, Jalali AR. Health tourism in Iran; identifying obstacles for development of this industry. Int J Travel Med Glob Health. 2014;1(2):89-94.

6. Zamani-Farahani H, Henderson JC. Islamic Tourism and managing tourism development in Islamic societies: the cases of Iran and Saudi Arabia. Int J Tourism Res. 2010;12(1):79-89.

7. Sarwar AM, Manaf NA, Omar A. Medical tourist's perception in selecting their destination: A global perspective. Iran J Public Health. 2012;41(8):1-7.

8. Masoud F, Alireza J, Mahmoud K, Zahra A. A systematic review of publications studies on medical tourism. J Educ Health Promot. 2013;2:51.

9. Rokni L, Pourahmad A, Moteiey Langroudi MH, Rezaeiy Mahmoudi M, Heidarzadeh N. Appraisal the potential of central Iran, in the context of health tourism. Iran J Public Health. 2013;42(3):272-9.

10. Hajinejad A, Eslamfard F. Formulating strategies for the development of treatment tourism in Shiraz (Iran) using a strategic planning approach (SWOT). J Rafsanjan Univ Med Sci. 2013;12(8):641-54. Persian

11. Izadi M, Ayoobian A, Nasiri T, Joneidi, Fazel M, Hosseinpourfard MJ. Situation of health tourism in Iran; opportunity or threat. Iranian J Military Med. 2012;14(2):69-75.

12. Tabibi SJ, Nasiripour AA, Ayubian A, Mahmoodabadi HB. The Relation between Information Mechanisms and Medical Tourist
Attraction in Hospitals of Tehran, Iran. Health Info Manag. 2012;9(3):416-23. Persian

13. Jabbari A, Ferdosi M, Keyvanara M, Agharahimi Z. Stakeholders' analysis of the medical tourism industry: development strategies in Isfahan. J Educ Health Promot. 2013;2:44.

14. Lautier M. International trade of health services: Global trends and local impact. Health Policy. 2014;118(1):105-13.

15. Mirfakhradini SH, Mirfakhradini F, Sadr Bafghi SM. Investigating rate of iatric tourisms' satisfaction and prioritizing the effective factors on it via Fuzzy TOPSIS approach. J Shahid Sadoughi Univ Med Sci. 2012;20(5):668-78. Persian

16. Ranjbarian B, Khazaee Pool J, Balooyi Jam Khane H. Analysis of strengths, weaknesses, opportunities and threats of foreign tourists in Isfahan province using Fuzzy AHP. J Tourism Develop Plan. 2012;1(1):13-34.

17. Ferdosi M, Jabbari A, Keyvanara M, Agharahimi Z. Systematic Review of Publications on Medical Tourism. J Educ Health Promot. 2013;2:51.

18. Jesus JE. Ethical Challenges and Considerations of Short-Term International Medical Initiatives: An Excursion to Ghana as a Case Study. Ann Emerg Med. 2010;55(1):17-22.

19. Delgoshaei Jabbari A, Farzin MR, Sharbafchizadeh N, Tabibi SJ. Current medical tourism: A Case Study of Iran. Payesh. 2012;11(2):171-9. Persian

20. Fatemeh Azadi, Mohammadreza Maleki, Seyed Jamaledin Tabibi, Mohammad Azmal. A Medical Tourist Perception of Iranian Hospital Quality: Limited Employee Foreign Lan-guage Skills Negatively Impact Communication. Int J Hosp Res. 2012;1(2):85-90.

21. Khodayari Zarnagh R, Tourani S, Ghaderi A, Salehi M, Jafari H. Assessment capabilities of hospitals of tehran university in medical tourism on the patient-centered standards of International Joint Commission. Hosp J. 2010;9(3-4):51-6. Persian

22. Khoshmohabat H, Motamedi M, Saghafinia M, Shams A. Immigration for health care in Iran: burden or blessing? Lancet. 2014;383(9922):1039.

23. Morovati Sharifabadi A, Asadian Ardakani F. A model for health tourism development using Fuzzy TOPSIS and interpretive structural modeling in Yazd province. Health Manag J. 2014;17(55):73-88.

24. Hadizade Moghadam A, Zahedian Nejad MH, Ghanbarzade Miandehi R, Fakharmanesh S. Model of the factors affecting the motivation of medical tourists to enter Iran. J Business Admin Outlook. 2013;15:59-79.

25. Ormond M. Shifting subjects of health-care: placing "medical tourism" in the context of Malaysian domestic health-care reform. Asia Pac Viewp. 2011;52(3):247-59.

26. Aref F. Barriers to community capacity building for tourism development in communities in Shiraz, Iran. J Sustain Tourism. 2011;19(3):347-59

27. Tabibi SJ, Tourani S. Medical Tourism in Iran: Analysis of Opportunities and Challenges with MADM Approach. Res J Biol Sci. 2010;5(3):251-7. 